\title{
MUDANÇAS ESTRATÉGICAS EM ORGANIZAÇÕES HOSPITALARES: uma abordagem contextual $\mathrm{e}$
} processual

\author{
Maurício Fernandes Pereira \\ Mestre e Doutorando em Engenharia de Produção pela Universidade Federal de Santa \\ Catarina (UFSC), Professor do Departamento de Ciências da Administração e do Núcleo \\ de Pesquisas e Estudos em Recursos Humanos (NUPERH) da UFSC e Coordenador dos \\ Cursos de Pós-Graduação em Gestão Empresarial, Gestão Estratégica de Recursos \\ Humanos, Gestão de Empresas no Comércio e Desenvolvimento Gerencial da UFSC. \\ E-mail:mpereira@cse.ufsc.br
}

\section{RESUMO}

O objetivo central do artigo consiste em verificar como ocorreu o processo de mudança estratégica em uma organização hospitalar. Analisam-se, de forma empírica, as mudanças estratégicas ocorridas nos últimos 20 anos no Hospital CBS. São identificadas as condições objetivas do setor - ambiente real, arena cognitiva - como ambiente percebido e a rede de colaboradores que dão suporte às atividades do hospital. O período de mais transformações foi o de 1991 a 1995, e as principais mudanças foram na cultura do hospital, na filosofia de trabalho dos médicos e funcionários, na forma de treinamento dos funcionários, na estrutura organizacional, nos processos e na tecnologia. Detectou-se que a coalizão dominante do hospital sofre apenas influência externa em razão das mudanças tecnológicas e que, internamente, o corpo clínico tem controle sobre o processo de tomada de decisões.

\begin{abstract}
The main purpose of this article is to verify how the process of strategic change happened in a hospital organization. An empiric analysis of the strategic changes that occurred in CBS Hospital in the last 20 years is developed. The direct conditions (real environment, cognitive arena) of the sector are identified as perceived environment and the network of collaborators that support the hospital's activities is determined. The period of major transformation was from 1991 to 1995, and the main changes were in the hospital culture, the doctors' and staff's work philosophy, the training way of the staff, the organizational structure, the process and the technology. It was perceived that the hospital dominant coalition is affected just by external influence due to some technologic changes and that, internally, the clinic body has control over the decision making process.
\end{abstract}

PALAVRAS-CHAVE

Mudança estratégica, condições objetivas, arena cognitiva, rede colaborativa.

KEY WORDS

Strategic change, direct conditions, cognitive arena, collaboration network. 


\section{INTRODUÇÃO}

As mudanças nos panoramas político, econômico, social, tecnológico, cultural, demográfico e ecológico (Hall, 1984) têm inspirado grandes transformações nas estratégias empresariais das organizações. Para enfrentar tal conjuntura, as novas formas organizacionais devem ser flexíveis, adaptativas e responsivas às necessidades dos clientes e dos requisitos do mercado (Craves, Shipp e Craves, 1994), tendo em vista que as organizações também estão em contínuas mudanças.

Desse modo, como afirma Theobald (1994), vivese tempos turbulentos, em que mudanças ambientais estão ocorrendo por toda parte. As alterações são tão intensas que alguns estudiosos classificam a presente era como a da mudança da mudança (Ferguson, 1980). Theobald (1994) e Drucker (1995) afirmam que nenhum século da história da humanidade passou por tantas transformações radicais quanto este. A mudança é um processo que invade a vida das pessoas, bem como o contexto das organizações. O conceito de "choque do futuro", introduzido na década de 70 por Toffler (1970) para descrever a tensão e a grande desorientação sofridas pelas pessoas quando sujeitas a uma carga de mudança muito grande num espaço de tempo curto, serve muito bem para explicar o momento de angústia pelo qual a maioria das organizações passam hoje em dia.

Como argumentam Dunphy e Stace (1988), tempos radicais podem requerer remédios radicais, ou seja, em momentos de crise, a organização deve mudar e adaptar-se rapidamente. No entanto, Pettigrew (1985) lembra que é clara a associação entre distúrbios ambientais e períodos de importantes mudanças. Contudo, não se deve esquecer que, geralmente, uma crise pode acelerar o processo de mudança. Entretanto, mudanças radicais não são as ideais, pois uma organização muito grande não consegue alterar suas estratégias e sua estrutura no momento exato em que ocorrem as pressões e instabilidades ambientais (Peters, 1993).

Por isso, tanto flexibilidade quanto objetividade são essenciais para o êxito de um processo de mudança (Judson, 1980) e adaptação estratégica, a fim de que, ao término do curso, possa haver um aumento de produtividade (Kirkpatrick, 1988) e uma melhora nos níveis de performance (Gronhaug e Falkenberg, 1989).

Mudança organizacional é um processo multinível e interativo, tendo seus resultados moldados por interesses e compromissos, tanto no nível do indivíduo como no nível dos grupos de dentro da organização. Ela resulta da escolha, do determinismo e da interação de várias forças políticas e econômicas.
Diante disso, é sabido que as organizações não possuem controle das condições necessárias para sua própria sobrevivência, sendo elas importadoras de recursos externos. Logo, dependem do ambiente. Por ambiente entende-se os elementos que a organização não pode controlar, embora ela possa ser capaz de influenciar o seu ambiente local de algum modo. Assim, a sobrevivência organizacional depende não apenas de ajustes internos mas também, principalmente, de ajustes e lutas com o ambiente externo.

A natureza do ambiente em que a organização está inserida é quase sempre conceitualizada como algo a ser adaptado ou controlado. Dessa forma, a organização pode adaptar sua estrutura, seu sistema de informações, seus modelos administrativos e de relações humanas, sua tecnologia, seus produtos, seus valores e suas normas ou pode, ainda, adaptar sua definição de ambiente.

Nessa linha, as organizações, para serem competitivas e lucrativas (Hall, 1984), precisam ser permeáveis ao meio ambiente, ou seja, devem manterse atentas às suas alterações, não deixando de perder de vista o referencial ambiental como o principal tópico do processo de mudança e adaptação estratégica. Todavia, há dois problemas peculiares à adaptação organizacional: a rapidez com que as mudanças ocorrem e a dificuldade de se ter uma exata predição do futuro, no correto e preciso instante em que elas irão ocorrer, a fim de se conseguir reduzir o efeito negativo ao máximo.

Assim, o referencial teórico utilizado para operacionalizar a presente pesquisa - sobre as mudanças estratégicas organizacionais ocorridas no Hospital CBS (nome fictício, respeitando a decisão da Diretoria do hospital de não revelar o nome original) ao longo dos últimos 20 anos - fundamenta-se em Child (1972), essencialmente, no modelo firm-in-sector explicado por Child e Smith (1987). Segundo esse modelo, o ambiente real da organização (definido por eles como as condições objetivas do setor), a arena cognitiva (ou seja, a percepção do ambiente pelos tomadores de decisão) e a rede colaborativa (na qual são trocados recursos como tecnologia e informação) são os elementos que determinam a direção das transformações das organizações. A presente pesquisa foi desenvolvida sob a égide desse modelo. Para tanto, deseja-se investigar, por meio de um caso real, o seguinte problema de pesquisa: Como se deu o processo de mudança estratégica no Hospital CBS nos últimos 20 anos? Dessa maneira, cinco são as perguntas que orientam o trabalho:

a) Quais eram as condições objetivas do setor no período estudado? 
b) Qual era a arena cognitiva?

c) Como era a rede colaborativa?

d) Quais foram as mudanças estratégicas ocorridas?

e) Quais fatores levaram a organização a implementar as mudanças?

\section{PREMISSAS BÁSICAS}

\section{Mudança e adaptação estratégica}

Partindo-se do princípio de que todas as organizações, bem como seus ambientes, estão continuamente em mudança, podendo elas próprias redefinir, mudar e influenciar seu ambiente em causa própria, o processo de mudança é como se fosse um processo de aprendizagem, em que a organização está ininterruptamente reavaliando seus processos para detectar os pontos de acertos e os pontos em que foram cometidos desvios.

Um processo de mudança é algo muito mais amplo do que o puro entendimento de simples dimensões ambientais. A mudança estratégica é, antes de tudo, um processo político que implica a modificação da distribuição de recursos e de poder pelos vários níveis ou unidades organizacionais (Hutt, Walker e Frankwick, 1995).

Para entender a conjuntura atual, Theobald (1994) alerta que se vive um novo tipo de turbulência ambiental, resultante da combinação de uma série de fatores - social, político, técnico, mudanças de mercado, entre outros -, que é diferente de qualquer experiência anterior na história da humanidade. Com isso, as organizações adaptativas vislumbram as turbulências ambientais como uma oportunidade para a inovação e a criatividade, admitindo-se, assim, que as organizações podem freqüentemente mudar em resposta às condições ambientais. Portanto, quase todas as organizações introduzem pelo menos pequenas mudanças adaptativas; uma vez que desejam sobreviver às turbulências, elas têm que se adaptar às mudanças do meio ambiente (Robbins, 1990).

No mesmo foco de análise de Robbins (1990), Alexander (1991) considera que a primeira, e talvez a mais importante, suposição no estudo das organizações é a de que a organização pode adaptar as suas práticas para se ajustar às principais mudanças que ocorrem no ambiente em que atua. Schreuder (1993) vai mais além, admitindo que todas as organizações tentam se adaptar às circunstâncias da mudança, visto que as organizações não são completamente inertes.

Conforme McKinlay e Starkey (1988), quando as organizações são defrontadas com turbulências am- bientais, o seu interesse se volta para obter formas organizacionais que permitam rapidez e flexibilidade nas respostas ao meio e às mudanças. Justamente flexibilidade e antecipação às crises são dois dos fatores básicos considerados por Hegarty (1993) para o sucesso organizacional. Sob essa óptica, Robbins (1990) concorda com McKinlay e Starkey (1988) e com Hegarty (1993), destacando que os processos de mudança exigem, além de flexibilidade e inovação, respostas rápidas.

Logo, o estudo de caso visualiza como o hospital efetua suas escolhas e como procura obter vantagens da percepção de sua coalizão dominante à luz da interação meio ambiente versus organização. A ponderação também é importante devido ao fato de que estas discussões servem para dar consistência à adoção do modelo de Child e Smith (1987) para o estudo da mudança estratégica organizacional no Hospital CBS.

\section{É sabido que as organizações não possuem controle das condições necessárias para sua própria sobrevivência, sendo elas importadoras de recursos externos. Logo, dependem do ambiente.}

\section{Mudança estratégica organizacional: uma framework}

As organizações são instituições sociais com culturas e histórias próprias. Em consonância com esses elementos e para enfatizar a discussão, Greenwood e Hinings (1988) evocam Pettigrew para afirmar que as possibilidades e as limitações da mudança em qualquer organização são influenciadas pela história, pelas atitudes, pelos relacionamentos entre os grupos de interesse e pela mobilização para a mudança dentro da estrutura de poder e que o real problema da mudança estratégica está ancorado, principalmente, nos novos conceitos da realidade e nas novas questões e idéias que requerem atenção (Pettigrew, 1985) e que perpassam as organizações e seus ambientes.

Foi comprovado, por meio de estudos de Child (1972), que as organizações podem, de fato, responder às mudanças em seu ambiente pela iniciativa de processos de mudança estratégica. Desse modo, a energia para a mudança estratégica é baseada no reconhecimento da pressão ambiental e no prematuro senso de disparidade entre a organização do presente e seus desejos futuros de relacionamento com seus 
ambientes competitivo, social, político e econômico (Pettigrew, 1985), ou seja, com seu contexto externo.

Quando, no passado, o ritmo das transformações seguia um curso lento, podia-se tomar as experiências de hoje e do passado para se ter uma perspectiva no futuro. Atualmente, porém, as mudanças acontecem cada vez mais rapidamente, e as organizações, constituídas como sistemas complexos, têm de aceitar que a premissa de épocas passadas já não vale mais para o presente e nem mesmo pode compor referências consistentes e confiáveis para o futuro. Em resumo, as organizações complexas não necessariamente se comportarão no futuro nem se comportam no presente como se comportavam no passado.

Discordando da visão determinística de alguns autores, Pettigrew (1990) adverte que as organizações, mesmo sofrendo pressões do meio, têm a possibilidade objetiva de fazer escolhas quanto a ações e estratégias, mesmo que limitadas pelas mudanças do contexto dos negócios.

Os estudos de Child e Smith (1987) tendem a focalizar a organização como a unidade de análise, dispensado maior ênfase na capacidade da administração em analisar o ambiente competitivo. Nos estudos de Pettigrew, Ferlie e McKee (1992), é enfatizado o papel das políticas no contexto organizacional, observando a tomada de decisão e a mudança como um processo contínuo. Desse modo, pode-se dizer que os trabalhos de Child e os de Pettigrew procuram demonstrar a justaposição de fatores racionais, ideológicos, políticos e de mercado, determinando a direção e o processo da mudança.

Portanto, é evidente em estudos recentes, mormente os encetados por Child e por Pettigrew, a tentativa em apresentar uma nova visão, mais realista, para pensar o processo de mudança. Nessa nova óptica, a mudança estratégica é vista “(...) como um processo humano complexo em que todos desempenham sua parte: a percepção diferenciada, as buscas por eficiência e poder, as habilidades de liderança visionária, a duração das mudanças e processos sutis que gradativamente preparam o momento de apoio para mudança e, então, a implementação vigorosa da mudança" (Pettigrew, 1990).

No modelo elaborado por Child e Smith (1987), a figura da liderança não é tão relevante; a questão central passa a ser a coalizão dominante. Há, no modelo, a possibilidade de existir um espaço de decisão, definido e exercido pela coalizão dominante da organização. É um modelo que derruba a visão causal e apresenta uma visão política como a mais ideal, a mais subjetiva, ou seja, o ambiente percebido (Bowditch e Buono, 1992) passa a ser considerado um importante elemento para o estudo do processo de mudança.

O modelo de Child e Smith (1987) denominado firm-in-sector relaciona três pontos cruciais para a transformação organizacional: a) o setor constitui um conjunto de condições objetivas, o qual pode criar pressões para transformações; b) o setor é uma arena cognitiva com a qual seus membros se identificam e c) o setor não consiste apenas em produtos competitivos mas também em uma rede de colaboradores atuais e potenciais.

As condições objetivas do setor constituem-se das condições tecnológicas, sociais, econômicas e questões legais, entre outros elementos, que exercem pressão para a transformação nas organizações.

Da arena cognitiva fazem parte os valores ou as ideologias a respeito de qual desenho e quais objetivos organizacionais são legitimados, bem como as crenças e experiências de vida de cada indivíduo. Portanto, ela é constituída a partir da percepção da coalizão dominante. $\mathrm{O}$ termo arena cognitiva é encontrado na literatura como sinônimo de ambiente percebido, funcionando como um filtro da relação entre ambiente e organização. Embora as características organizacionais sejam freqüentemente moldadas diretamente pelos fatores externos, muitas delas refletem uma interação entre o ambiente e as preferências, percepções e escolhas daqueles que controlam as principais decisões - a coalizão dominante -, sendo essas preferências, percepções e escolhas elas mesmas afetadas pelas atitudes, pelos valores e pelas crenças da própria coalizão dominante (Provan, 1991). Em outras palavras, a arena cognitiva reflete a interpretação subjetiva do ambiente real da organização.

A rede de colaboradores compõe-se da rede social de relacionamento da empresa com seus fornecedores e demais atores que trocam informações. São os canais para compartilhar informações e recursos com colaboradores atuais e potenciais.

Segundo Provan (1991), as organizações consistem em várias coalizões, de indivíduos ou grupos, e as decisões são arquitetadas por aquelas coalizões que são as dominantes. Por coalizão dominante, Miles e Snow (1978) entendem um elemento que existe em toda e qualquer organização e é caracterizado por um grupo de tomadores de decisões que influencia o sistema de forma muito acentuada. Esse grupo de indivíduos tem a responsabilidade tanto de identificar quanto de resolver os problemas, e, por meio das percepções, a coalizão dominante decreta ou cria o meio ambiente relevante da organização. Portanto, a organização responde amplamente àquilo que sua administração percebe.

Diante do exposto, a postura adotada neste artigo 
é a perspectiva histórica, contextual e longitudinal, pesquisada, principalmente, sob a égide dos estudos sobre os processos de mudanças estratégicas organizacionais de Child e Smith (1987), nos quais os elementos do modelo firm-in-sector - condições objetivas, arena cognitiva e rede colaborativa - fornecem as bases teóricas para o estudo de caso desenvolvido no Hospital CBS.

\section{METODOLOGIA}

\section{Especificação do problema}

Utilizou-se como base para a elaboração da metodologia o fato de que se deve realizar uma análise histórica a fim de examinar as questões que envolvem o estudo dos processos de mudança estratégica. O elemento tempo real é comumente uma referência que afeta diretamente a percepção da mudança (Van de Ven, 1992). Em vista disso, é importante conduzir estudos longitudinais em tempo real de mudança para se conseguir uma variedade de desenhos e padrões organizacionais de mudança (Kikulis, Slack e Hinings, 1995). Sem dados longitudinais, é impossível identificar a dinâmica processual da mudança, a relação entre forças de continuidade e de mudança e, portanto, a inseparável ligação entre estrutura e processo (Pettigrew, 1985).

\section{Design e perspectiva da pesquisa}

A pesquisa utilizou um design do tipo levantamento, coletando-se dados de toda uma população ao longo de um período de 20 anos. Nesse sentido, a pesquisa visa a estudar basicamente as mudanças estratégicas de uma organização durante o período especificado, configurando-se, assim, não apenas como um estudo longitudinal mas também processual (Pettigrew, 1985).

O método da pesquisa é o estudo de caso único (Yin, 1989) como unidade de análise: uma organização hospitalar. O estudo de caso caracteriza-se como um estudo em profundidade baseado numa análise intensiva empreendida em uma única organização (Bruyne, Herman e Schoutheete, 1991).

\section{População}

O universo da pesquisa compreende o setor de saúde, especificamente o caso das organizações hospitalares. A amostra da pesquisa foi intencional, constituindo-se de um hospital filantrópico, justamente por se tratar de um estudo de caso único. Cabe ressaltar que, na escolha do hospital estudado, levou-se em conta, além de outros fatores, principalmente o fato de este ser um hospital muito antigo (fundado em 1782) e um centro de referência para o contexto catarinense.

A investigação ocorreu por meio de entrevistas com os membros da coalizão dominante, representados pelas três últimas instâncias de poder de decisão na estrutura do Hospital CBS, respectivamente e de forma hierarquicamente crescente: a Diretoria Executiva, a Mesa Administrativa e o Conselho Pleno. Foram também entrevistados - para melhor compreensão, sem, no entanto, se prender a detalhes - outros membros da organização que não participam da coalizão dominante, mas que têm conhecimento amplo de todo o processo da organização, incluídos entre eles o responsável pelo setor de recursos humanos e finanças do hospital e médicos e enfermeiros, totalizando algo em torno de 14 entrevistas.

\section{A sobrevivência organizacional depende não apenas de ajustes internos mas também, principalmente, de ajustes e lutas com o ambiente externo.}

\section{Coleta e análise dos dados: tipos e técnicas}

Os dados primários foram coletados por meio de entrevistas semi-estruturadas. As entrevistas foram direcionadas mais para os membros da coalizão dominante do Hospital CBS (Diretoria Executiva do CBS, Mesa Administrativa e Conselho Pleno). Foi feita uma análise documental para obtenção de dados preliminares do hospital e do setor de saúde. Assim, essa análise constituiu-se num importante instrumento de coleta de dados secundários.

\section{Tratamento dos dados}

O tratamento dos dados foi realizado a partir de uma análise descritiva à luz dos conceitos do modelo firm-in-sector. Como afirma Yin (1989), a análise dos dados em um estudo de caso consiste na compreensão dos dados a fim de validar ou refutar os objetivos iniciais do estudo, ou seja, as bases do modelo proposto por Child e Smith (1987). Com base nisso, foi realizada a análise dos dados qualitativos do presente estudo de caso, assim como na assertiva de Selltiz et al. (1974), que observam que o objetivo da análise dos dados é sintetizar as informações completadas, de forma que estas viabilizem respostas às perguntas da pesquisa em foco. Por fim, uma das últimas versões do caso empírico foi submetida a um dos atores do hospital, pois, como observa Gutierrez (1996), tal 
prática possibilita não só a correção e a clarificação dos dados, mas, sobretudo, a validação da pesquisa.

\section{APRESENTAÇÃO DOS DADOS}

\section{Condições objetivas do setor}

Da mesma forma que em outros tipos de organizações, os hospitais são diferenciados pelas dimensões demográfica, política, social, tecnológica, ambiental e econômica. Dimensões essas que, além de influenciarem muitos aspectos, determinam o investimento do setor (Bittar e Mieldazis, 1992). Assim, as organizações hospitalares devem ter uma gestão orientada para o meio externo e devem adaptar-se às mudanças de todas essas dimensões. Devido a tais aspectos, os hospitais devem possuir formas organizacionais flexíveis, adaptativas e permeáveis ao ambiente.

Contextualizando o sistema de saúde brasileiro, ele se encontra no mais alto nível de degradação e abandono. Uma maneira de se visualizar a questão é por meio das organizações hospitalares. Pode-se perceber, entre outras coisas, em todos os cantos do país, filas quilométricas de pessoas esperando para serem atendidas, chegando-se a ter pacientes morrendo nas filas de espera, pessoas esperando em macas nos corredores para serem operadas e hospitais sendo fechados. É um descaso generalizado com o atendimento.

A crise no sistema de saúde brasileiro, mormente nas organizações hospitalares, vem de longa data. Em 1978, o estado calamitoso era evidente diante da crise previdenciária ocasionada por uma infinidade de fatores de natureza estrutural, bem como devido à conjuntura econômica do país, que estava se agravando. Foi a partir desse momento que a Previdência, via Instituto de Assistência Médica da Previdência Social (Inamps), tentou controlar seus gastos com assistência médico-hospitalar. Para isso, dois mecanismos foram utilizados, um para fiscalizar as contas de forma mais rigorosa e outro para reduzir progressivamente os valores pagos pelos atos médico-hospitalares e pelas diárias (Ribeiro, 1983). Sobre o conjunto das duas medidas, pode-se dizer que não apenas não surtiu os efeitos esperados, como também acelerou o processo de sucateamento da rede hospitalar, pois o segundo mecanismo fez aumentar as fraudes nos exames: "cesarianas feitas em homens", "operações de fimose em mulheres" e assim por diante.

Tudo isso é fruto da maneira pela qual ocorreu o desenvolvimento da rede hospitalar no Brasil, identificado muito mais por necessidades sentidas, definições políticas localizadas e interesses de certos grupos do que especificamente em função de uma política nacional de saúde, como descreve Castelar (1995).
É bom lembrar que, ao longo dos anos, as organizações hospitalares vêm sendo sucateadas, devido às freqüentes crises econômicas do Estado brasileiro, bem como pelo desleixo dos gestores públicos em relação à administração da saúde no país. Para se ter uma idéia da gravidade da situação, com a aceleração do processo inflacionário a partir de 1983, a penúria nos hospitais se agravou, com os recursos federais sendo repassados aos hospitais para o pagamento dos serviços prestados com até 80 dias de atraso. Como o valor já era baixo e não era corrigido, quando chegava aos hospitais, o dinheiro era ínfimo. Hoje, segundo os Diretores do Hospital CBS, a situação é "menos pior" porque os valores pagos pelo Sistema Único de Saúde (SUS) referentes às diárias não são consumidos pela inflação. Médici (1994) complementa dizendo que os atrasos e o não-comprometimento do Estado com a saúde são, antes de tudo, problemas de falta de planejamento e racionalidade (Viana, Queiroz e Ibanez, 1995).

A evolução dos gastos federais com saúde mostra que, em 1978, estes representavam $2,21 \%$ do orçamento global da União e, em 1979, representavam $1,82 \%$, gastos pequenos em vista de outros ministérios. Outros dados mostram que, em 1985, as despesas do Inamps corresponderam a $21 \%$ do dispêndio do Ministério da Previdência e Assistência Social. Os gastos com assistência médica do Inamps em 1984 foram inferiores aos gastos do antigo Instituto Nacional de Previdência Social (INPS); em 1975, dos gastos totais com saúde no Brasil, cerca de 41,6\% foram gastos efetuados pelo Estado (nas três esferas) e 58,4\% pelo setor privado.

O período de 1987 a 1989 comporta os anos em que os gastos federais com a saúde foram os mais altos de sua história, ficando em média acima dos US\$ 10 bilhões. Assim, os anos 80, mormente o final da década, foram um período em que os gastos com saúde, e conseqüentemente com os hospitais, vinham aumentando. No entanto, nos primeiros anos da década de 90, o quadro se reverteu. Os recursos federais investidos em saúde têm sofrido fortes quedas sem que estados e municípios aumentem suas contrapartidas no mesmo patamar que a queda verificada pela União.

A política nacional de saúde no Brasil é prevista nos artigos 196 e 200 da Constituição Federal de 1988. Advindo do texto constitucional, surge o SUS, criado para todo o território brasileiro, hierarquizando a prestação de serviço e descentralizando as ações para os estados e municípios, levando à extinção do Inamps em 1993.

Em 1988, é criado também o Orçamento da Seguridade Social (OSS) como uma fonte de financi- 
amento das ações no campo da previdência e assistência social, saúde e amparo ao trabalhador (Médici, 1994). No entanto ele começa a vigorar só em 1991. Até então, o grande financiador da saúde era o Fundo de Previdência e Assistência Social (FPAS).

Em suma, as estatísticas apresentadas comprovam que o Estado vem diminuindo seus investimentos no setor de saúde e, por conseqüência, na rede hospitalar do país. Dados do Banco Mundial (Médici, 1994) mostram que, em 1993, as três esferas desembolsaram em ações no setor de saúde em geral o irrisório percentual de $2,53 \%$ do PIB, enquanto os países de economias desenvolvidas chegam a gastar mais que o dobro.

\section{Arena cognitiva}

O Hospital CBS é administrado por uma entidade de fins filantrópicos. Tal entidade tem como órgão máximo de decisões o Conselho Pleno, formado por 44 conselheiros e presidido por um Provedor, que também é o presidente da Mesa Administrativa, órgão hierarquicamente abaixo ao Conselho Pleno. A Mesa indica a Diretoria Executiva do hospital, com exceção do Diretor Clínico, que é eleito pelo corpo médico do hospital. Da Diretoria Executiva fazem parte, também, um Diretor Técnico, um Diretor Administrativo e um Diretor Tesoureiro.

O poder no Hospital CBS está fundamentalmente nas mãos do presidente da Mesa Administrativa e do Conselho Pleno, que é a mesma pessoa; suas decisões quase nunca são reprovadas, tamanha a sua influência sobre os demais integrantes. Assim, a estrutura de poder no CBS é altamente centralizada.

A Diretoria Executiva tem um poder limitado, visto que as decisões de grande porte têm que ter o prévio aval da Mesa. No entanto, as decisões de pequeno porte não necessitam de um aval anterior. Mesmo assim, a Diretoria Executiva tem de informar e prestar contas à Mesa de seus atos. O mesmo pensamento é usado para as gerências: pequenas decisões são livres, podendo ser tomadas diariamente, obviamente, prestando contas à Diretoria Executiva posteriormente. No entanto, grandes decisões que possam causar repercussões maiores têm que ser previamente autorizadas pela Diretoria. Desse modo, pode-se dizer que a coalizão dominante na estrutura de poder do Hospital CBS é centralizada em três elementos, como demonstra um dos Diretores: "Nada influencia a diretriz do Hospital CBS, a não ser a sua Provedoria e a própria Dire- ção do hospital." O pensamento de uma coalizão dominante forte no Hospital CBS sempre existiu. Todavia, com os novos tempos, de 1991 para cá, a tecnologia é um fator considerado como um elemento influenciador do processo de tomada de decisão da cúpula do hospital.
As organizações adaptativas vislumbram as turbulências ambientais como uma oportunidade para a inovação e a criatividade. Assim, as organizações mudam em resposta às condições ambientais.

No entanto, pode-se perceber que as decisões não são apenas top-down, mas também, em alguns casos, são botton-up, como relatou um Diretor. No entanto, com certeza, a maioria das decisões são top-down, segundo a pesquisa: "A Diretoria Administrativa toma a decisão e empurra mesmo para as chefias e para os funcionários em geral, mas passa para a Mesa Administrativa para ela tomar conhecimento." Evidentemente, as decisões tomadas pela Mesa Administrativa muitas vezes não são as melhores, por sua composição não ser profissional e, sim, de pessoas abnegadas que contribuem gratuitamente com a Provedoria e com o hospital.

Segundo os Diretores do Hospital CBS, o problema da crise do país não está na falta de hospitais e sim na falta de serviços ambulatoriais que deveriam ser prestados em postos de saúde, pois cerca de $80 \%$ dos casos atendidos pela emergência do Hospital CBS são de consultas corriqueiras, pequenas e médias urgências, que deveriam ser tratadas em ambulatórios ou postos de saúde. Nos postos de saúde, na maioria das vezes, o médico atende dez pessoas e vai para o seu consultório ganhar dinheiro, pois o pagamento do SUS é irrisório. Sem contar que existem mais ou menos $20 \%$ de municípios no Brasil sem um único posto de saúde, ocasionando enormes filas nas portas dos hospitais.

Dentro de todo esse contexto, o Hospital CBS veio caminhando até meados dos anos 60 em pequenos passos, sem nenhum alarde. Imediatamente à década de 60 , ele começou a viver seus tempos áureos com a instalação da antiga Faculdade de Medicina em suas dependências, com o objetivo de os alunos aprenderem a medicina prática. O Hospital CBS viveu aquele período sem se preocupar com recursos, uma vez que todas as suas contas eram pagas pelo governo federal. Logo, com a inauguração do Hospital Universitá- 
rio (HU) na Universidade Federal de Santa Catarina (UFSC), em 1980, todas as atividades feitas no CBS foram transferidas para o HU. Nesse momento, o CBS começa a se afundar, visto que sua cultura ainda estava impregnada em recursos fáceis do governo. No entanto, estes não mais existiam. Leitos e alas inteiras foram fechados; dos cerca de 400 leitos que o hospital possuía, este chegou ao final da década de 80 com apenas 90 leitos e falido.

No período de 1987 a 1989, alguns médicos começaram a se mexer a fim de conscientizar o corpo clínico de que algo teria de ser feito ou o hospital iria fechar completamente. Depois de dois a três longos anos de conscientização, em 1991, o CBS começa efetivamente a se reerguer, implementando mudanças reativas radicais para sair do fundo do poço.

Em 1995, com uma nova feição, em virtude da revolução havida, o CBS passou a ser classificado como um centro médico de referência em todo o estado de Santa Catarina, como relatou um Diretor do CBS: "Hoje o CBS é o hospital mais bem equipado de Santa Catarina. Fizemos medicina de Primeiro Mundo. (...) Nenhum hospital faz o que o CBS faz, ou seja, tratar ao mesmo tempo e sob uma só instituição todas as especialidades, todas."

Em vista disso, é fato constatado que os momentos de inércia vividos pelo Hospital CBS por quase toda a década de 80 lhe proporcionaram não só uma crise financeira como também uma crise estrutural, acarretando problemas no funcionamento das atividades do hospital. A instituição não dispunha de equipamentos ou condições mínimas de funcionamento. Nas palavras de um Diretor: "O Hospital CBS em 1987, quando nós assumimos, (...) não tinha nada." Foram as mudanças que ocorreram a partir de 1991 e que ainda ocorrem que proporcionaram ao CBS chegar à tecnologia, situação que, em tempos passados, era impossível; segundo um Diretor: "(...) estamos num processo de mudança, as mudanças são constantes."

Para concluir e explicitar ainda mais a arena cognitiva, variável interveniente no presente estudo, Gutierrez (1996) faz um importante esclarecimento: "Nesta pesquisa valorizam-se de maneira central as diferentes percepções e representações mentais dos atores envolvidos nos processos de mudança. Segundo esta perspectiva, a forma como os atores forjam seus conhecimentos contribui para construir as realidades sociais que fundamentam suas ações. Considerar que os contextos nos quais os dirigentes atuam podem ser mobilizados não quer dizer que esses contextos são entidades inertes ou objetivas. Ao contrário, são os atores - em particular os dirigentes - que, selecionando os elementos do contexto em função de seus próprios interesses e valores, constroem de determinada maneira esse contexto." Assim, como relatam Nadler, Hackman e Lawler III (1983), “(...) as pessoas percebem seu ambiente em função das suas necessidades e experiências passadas", mais especificamente se toma emprestado o esclarecimento de Gutierrez (1996) para afirmar que as mudanças estratégicas no CBS foram construídas a partir das percepções que a coalizão dominante fez do ambiente real do setor.

\section{Rede colaborativa}

É possível dividir a rede colaborativa do CBS em três elementos principais: a) recursos humanos, b) tecnologia e c) processos, incluindo os novos serviços provenientes das novas tecnologias e da agilidade dos próprios processos.

Quanto aos recursos humanos, o Hospital CBS vem aumentando o número de médicos credenciados que não são funcionários do hospital. O hospital apresenta uma variação decrescente ao longo dos anos no número de funcionários, mantendo o número de médicos que são funcionários. Em média, os funcionários têm de 19 a 30 anos e o $2^{\circ}$ grau completo. O grau de escolaridade é muito bom quando comparado com os hospitais públicos, tendo em vista que, de acordo com Pitta (1994), 50,4\% dos funcionários nunca freqüentaram uma escola ou têm apenas o $1^{\circ}$ grau completo.

Para possuir uma equipe médica altamente qualificada, proporcionando um fator de diferença em relação aos demais hospitais, o CBS exige, para integrar seu corpo clínico, médicos que tenham no mínimo um curso de especialização, com certificado reconhecido pelo Ministério da Educação. Toda essa preocupação do CBS em ter médicos capacitados deve-se ao fato de que o hospital sabe que depende fundamentalmente de seu corpo clínico. Os médicos do CBS atualmente têm uma preocupação toda especial com os pacientes e com o hospital em si e não estão preocupados apenas com o seu procedimento, mas também com o procedimento dos seus colegas de profissão, pois a sobrevivência do hospital depende do sucesso de todos. Essa situação, que anos atrás seria impossível, hoje é realidade.

Outro fator importante no CBS é que os cargos de Diretoria devem ser exercidos preferencialmente por médicos que tenham também cursos em Administração de Empresas ou Administração Hospitalar. Atualmente, o Diretor Técnico e o Coordenador-Geral do hospital, justamente as pessoas que, por volta de 1987 a 1989, iniciaram todo o processo de mudança organizacional no CBS, possuem cursos de Administração de Empresas e de Administração Hospitalar, respectivamente. 
O papel da tecnologia nesse processo todo foi muito importante. No entanto, essa palavra tinha significado desconhecido no vernáculo do Hospital CBS até os fins dos anos 80. Ela efetivamente só entrou em circulação quando os médicos foram chamados no início da década de 90 a participar financeiramente das atividades do hospital. Desde então, a realidade é completamente outra. Hoje há várias clínicas instaladas dentro do CBS, clínicas essas com as quais o CBS mantém participações acionárias além de receber o aluguel da área ocupada. Com as clínicas, por meio da terceirização e da parceria, foi possível a tecnologia chegar ao Hospital CBS.

No momento, o CBS possui não só os melhores médicos do estado em seus quadros, como também está à disposição de toda a população, independentemente de convênios, com tecnologia de Primeiro Mundo. Sem a conscientização dos médicos de que os investimentos próprios que eles iriam fazer no hospital acabariam por reverter não só em benefício do hospital e de toda a população, como também em seu benefício, via terceirização, o Hospital CBS nunca chegaria à tecnologia de ponta que alcançou. Esse é um fator importantíssimo no desenvolvimento e crescimento do CBS.

O CBS, por meio da sua Diretoria Executiva, possui uma rede de colaboradores tanto em nível nacional quanto em nível internacional, que o coloca em sintonia com o que há de mais moderno em termos tecnológicos. Isso proporciona ao CBS estar sempre atualizado em termos de tecnologia de ponta na área médica, como os últimos aparelhos médicos lançados e as últimas técnicas médicas que ainda estão em estudo.

\section{ANÁLISE E DISCUSSÃO DOS RESULTADOS}

Para melhor compreensão das transformações e mudanças estratégicas no Hospital CBS, fez-se uma divisão cronológica em cinco períodos distintos:

a) de 1782 , data da fundação do CBS, até 1965 , com a instalação da antiga Faculdade de Medicina nas dependências do hospital;

b) de 1965 até 1980, com a transferência da Faculdade de Medicina para o HU;

c) de 1980 até 1987 , período em que o hospital começou a funcionar sem os recursos oriundos do governo federal;

d) de 1987 a 1990, período de transição e de conscientização, momento que o hospital parou para repensar seu papel e suas atividades;

e) de 1991 a 1995, período de crescimento com grandes transformações.

O primeiro período da história do Hospital CBS

(de 1782 a 1965) é caracterizado por ser uma fase de extrema calmaria. O hospital, fundado para ser um asilo, começou a receber regularmente a visita de um médico que passava para verificar como estava a saúde dos idosos. Essa foi a primeira experiência no campo médico do Hospital CBS, para mais tarde se tornar propriamente um hospital.

Já no segundo período, por volta de 1965, com a utilização do Hospital CBS pela antiga Faculdade de Medicina, este vive o seu auge, segundo relatou um dos Diretores: "Um dos grandes momentos para o Hospital CBS foi a vinda do Hospital-Escola, ou seja, o vínculo com a universidade. Foi um dos momentos mais prósperos do Hospital CBS, porque tudo era pago pelo governo federal."

Assim foi toda a década de 70 , saboreando as benesses dos recursos federais. Todavia, se por um lado foi um momento áureo em termos de recursos financeiros, por outro, foi um período de inércia total sob o ponto de vista de ajustes, de mudanças e de grandes transformações. O hospital objetivamente parou de pensar durante todo o segundo período de sua história, ou seja, por 15 anos, como fruto da comodidade, diante do dinheiro fácil.

Nos anos 80, a inércia continua, só que os problemas se agravavam cada vez mais, pois, nesse momento, a Faculdade de Medicina se transferiu para o recém-inaugurado $\mathrm{HU}$, os recursos cessaram e o hospital foi ao fundo do poço. É o terceiro período e o pior período, como constata um Diretor: "O pior momento do hospital foi a saída exatamente da Faculdade de Medicina, tendo agora que caminhar com as suas próprias pernas. Mas o corpo médico e funcional raciocinava e trabalhava como se estivesse na universidade. Porém, os recursos não existiam mais."

Como é demonstrado pelo Diretor, a cultura (Vasconcelos, 1993; Wood Jr., Curado e Campos, 1994) anterior na instituição não tinha sido mudada e adaptada para os novos tempos. A década de 80 foi o pior momento do hospital, uma completa paralisia do CBS. O hospital chegou em 1987 com quase "nada em tudo", tanto em termos de equipamentos como em termos de infra-estrutura mínima para o necessário funcionamento.

Outro Diretor esclarece que os problemas não eram apenas financeiros, mas também existia um problema de comando. Até 1983, o Hospital CBS era comandado por um administrador que não era médico, e isso gerou sérios problemas com o corpo clínico do hospital. Foi a partir desse momento que o hospital começou a entrar no seu quarto período, por volta de 1987 e 1988 indo até 1990. Foi um período de transição muito importante para a consolidação das mudanças estratégicas que viriam a acontecer na década de 90 . 
Dois médicos encabeçaram todo o movimento. Foram tais médicos que começaram, mais ou menos em 1988, a se mobilizar a fim de conscientizar o corpo clínico de que algo teria de ser feito ou o hospital fecharia as suas portas.

O processo de conscientização foi feito por meio de várias reuniões tanto do corpo médico como do corpo funcional, perdurando por cerca de três anos, como explicou um Diretor: "Com o processo de conscientização e da sua aprovação pela maioria dos envolvidos, houve uma adesão de toda a estrutura do hospital, mesmo daquelas pessoas que a princípio não apoiavam o processo de mudança. Foi um processo de seleção natural, ou seja, se alguém não apoiasse ficaria alijado do processo e excluído da organização." Na realidade, alguns médicos, preocupados com o novo estado das coisas que poderia surgir, num primeiro momento, foram contra o processo de mudança. Essa força contrária, porém, aos poucos começou a se conscientizar das reais necessidades de iniciar um processo de profundas mudanças no CBS. Imediatamente, houve uma transformação de seus comportamentos e eles também se engajaram no processo de mudança.

Segundo os Diretores, o processo valeu a pena porque, já em 1991, o pensamento do corpo clínico tinha mudado completamente. Transformações haviam ocorrido com a própria cultura do hospital. Nas palavras deles, "A principal [transformação] foi a conscientização dos médicos e funcionários de que nós precisávamos de leitos e para isso nós precisávamos de alta rotatividade e atuação direta, porque [antigamente] era muito fácil deixar o paciente de 10 a 15 dias no hospital sem nenhuma necessidade. A grande mudança foi a preocupação do médico no auxílio à administração do hospital. Mas, para isso, houve - uns dois ou três anos antes de chegarmos a esse ponto trabalho em cima da conscientização. Os médicos tinham que se conscientizar de que o doente que tivesse que ficar 10 dias ia ficar 10 dias, não mais. Ele não pode ficar 15 dias". Foi a partir dessa passagem, com a mentalidade de todos preparada para enfrentar os processos de mudança, que grandes transformações começaram a ocorrer no Hospital CBS.

Assim, em 1991, inicia-se o quinto período do Hospital CBS, no bojo de toda uma conjuntura muito diferente daquela vivenciada nos seus três primeiros períodos, que dura até os dias de hoje. De 1991 em diante, todas as decisões do CBS são planejadas e arquitetadas pelo Diretor Técnico e pelo Diretor Tesoureiro em conjunto com a Mesa Administrativa, que, a partir daquela época, se tornou mais atuante, configurando a centralização do poder de decisão nessas pessoas sem sofrer qualquer influência do ambiente externo.
Por isso, os Diretores devem ter suas responsabilidades embasadas em uma análise contextualista, avaliando as mudanças nos meios econômico, social, tecnológico e político ao elaborar estratégias de mudança e conseqüentes estratégias de crescimento do hospital. Desse modo, a coalizão dominante, que é representada principalmente pelos seus Diretores e pela Mesa, mudou o Hospital CBS, como relatou de forma genérica um dos membros da própria coalizão dominante: "Mudou tudo, foi obrigado a mudar. (...) a mudança foi total, desde a parte administrativa-burocrática até o treinamento dos próprios funcionários. Hoje nós temos a agilização de todos os processos (...). Queira ou não queira, o processo todo teve de mudar. Assim, o processo mudou para agilizá-lo. Nós mudamos a cultura da medicina no estado, não mudamos só a cultura do Hospital CBS, as mudanças refletiram em todos os hospitais do estado."

Com a afirmação acima e com as entrevistas realizadas no hospital, cinco mudanças estratégicas substanciais foram identificadas: a) na cultura do hospital; b) na forma de trabalho dos médicos e funcionários e na forma de treinamento dos funcionários; c) na tecnologia do hospital; d) na estrutura do hospital e e) nos processos do hospital.

Em relação à cultura, houve uma modificação total. Antigamente, o médico vinha ao CBS, atendia seus pacientes e ia embora. Hoje, com a filosofia implantada, o médico participa ativamente da administração e procura agilizar o atendimento o máximo possível. O que aconteceu foi que os médicos foram conscientizados de que não poderiam ficar inertes aos problemas do hospital, precisavam fazer algo e fizeram. Atenderam ao chamado da administração do hospital e começaram a acompanhar mais de perto as atividades do CBS, bem como investiram dinheiro do próprio bolso, fato que antigamente seria impossível acontecer.

A reboque do processo de mudança cultural, vieram a mudança na forma de os médicos e funcionários atuarem e a modificação na maneira com que os treinamentos eram feitos. Antes, os médicos pensavam duas vezes se visitariam ou não determinado paciente, deixavam para depois. Hoje, o pensamento é outro, eles sabem que o hospital precisa de leitos, sabem que o paciente deve sair curado o quanto antes para ceder lugar a outro. Não pensam mais duas vezes. Os funcionários são treinados e preparados para certos tipos de epidemias que o hospital prevê que acontecerão. Por exemplo, no caso do surto de cólera em todo o país, o CBS estava preparado para receber doentes desse tipo, tanto em nível de funcionários e número de leitos quanto em nível de médicos e medi- 
camentos. Assim, o hospital consegue antecipar-se às epidemias e preparar todas as atividades de suporte para as doenças.

As mudanças tecnológicas estão centradas no processo de terceirização e parceria efetuado no CBS por meio de seu corpo clínico, segundo foi comentado: "Os primeiros passos em termos de tecnologia foram dados há cinco ou seis anos. A Diretoria Executiva chamou o corpo clínico, foram as maiores mudanças da história do hospital. (...) fizemos uma coisa inédita no país, chamamos os médicos para participarem financeiramente, através da terceirização. Eles construíram - cada grupo de médicos - clínicas, compraram os equipamentos e pagam aluguel e/ou dão um percentual do lucro."

Em cada clínica instalada no hospital, este possui uma participação acionária, o percentual varia de clínica para clínica. Todas as clínicas são de médicos credenciados no CBS, e são abertas novas clínicas de acordo com a necessidade. Atualmente, o CBS atende a todas as doenças e especialidades conhecidas na medicina. Não é fácil, porém, identificar o momento em que cada especialidade foi agregada ao rol dos serviços oferecidos pelo CBS, como explica um Diretor: "Isso é muito complexo. Nós começamos a terceirizar o hospital. Terceirizar o hospital também em parcerias, não entregando completamente o hospital. Passamos quase dois ou três anos por um processo de conscientização e, na hora em que a mudança aconteceu, ela aconteceu quase que num boom, um ano, dois anos aconteceu tudo. Não houve planejamento, nós sabíamos de todas as deficiências do hospital porque nós somos médicos (...)." Os médicos, todos, dentro de suas especialidades, se reuniam e estudavam o que se estava fazendo nos grandes centros e assim foram sendo agregadas novas tecnologias e novas técnicas médicas aos serviços prestados pelo CBS.

O Hospital CBS pode ser diferenciado do setor hospitalar em termos de condições objetivas por três motivos. Primeiro, ele é o único hospital de Santa Catarina que oferece todas as especialidades médicas, enquanto os outros se especializam em um determinado tipo de ação médica. Segundo, porque é o único hospital do estado que possui o aparelho para radioterapia com acelerador linear, aparelho de última geração. Por último, nas palavras de um Diretor: "O Hospital CBS é o único hospital no Brasil que faz psiquiatria, (...) o Hospital CBS já tem, tanto na farmaco-dependência (álcool e droga), como unidade psiquiátrica mesmo."
Com os novos tempos de mudança, chegou a informática no CBS. De 1991 para cá, alguns setores foram sendo informatizados. Alguns reflexos desse processo podem ser visualizados. Os dois mais significativos foram a diminuição do número de funcionários e a agilização de todos os processos, como cobranças e preparações prontuárias.

\section{Foi comprovado, por meio de estudos de Child, que as organizações podem, de fato, responder às mudanças em seu ambiente pela iniciativa de processos de mudança estratégica.}

Entendendo estrutura organizacional na concepção de Child (1972), ou seja, a) a alocação formal de regras de trabalho e b) os mecanismos de administração para controlar e integrar atividades de trabalho, podem-se obter duas conclusões do que ocorreu nestes últimos 20 anos no Hospital CBS. Até 1991, tanto no tópico (a) quanto no (b), não houve qualquer alteração. No entanto, depois de 1991, é claro perceber, de acordo com tudo o que foi relatado até o momento, que ocorreram profundas modificações no tópico (a), consoante as formas de trabalho e de treinamento introduzidas. Todavia, o (b) em nada foi alterado, os mecanismos são os mesmos, altamente centralizadores e dominadores.

No que concerne aos processos, a relação é a mesma, os mecanismos não mudaram. No entanto, eles foram agilizados, mesmo porque é uma necessidade do hospital, já que as mudanças que estão ocorrendo no hospital são contínuas e constantes.

Gladstein e Quinn (1985) corroboram o que aconteceu no CBS, pois afirmam que, geralmente, uma crise pode acelerar os processos de mudança. No CBS foi justamente o que aconteceu. A crise dos anos 80 forçou o hospital a implementar profundas transformações, como foi constatado nas entrevistas: "As mudanças que ocorreram foram extremamente reativas, nós estávamos sem condições de trabalho e fomos à luta (...)."

No entanto, a situação do hospital hoje é completamente diferente. As mudanças agora são planejadas, como explicou um Diretor: "(...) hoje nosso pensamento é que o equipamento que compramos [hoje] daqui a dois anos já vai estar obsoleto, então já estamos nos preparando para isso."

Houve fortes mudanças no CBS, e as alterações não param, o processo é contínuo e as transformações são constantes. Hoje, um dos pontos fortes do hospital são 
os equipamentos de última geração e únicos no estado. Equipamentos esses que foram adquiridos à medida que o hospital foi crescendo e sentindo a necessidade de melhoria. Todas as aquisições foram feitas pautadas nas percepções do corpo clínico, bem como nas mudanças tecnológicas que vinham ocorrendo via compreensão da Diretoria Executiva. O que influencia as escolhas estratégicas do hospital é exclusivamente o processo de inovação tecnológica. Assim, as mudanças no ambiente competitivo são mais rápidas do que a capacidade de respostas das organizações (Reynierse, 1994), o que foi procedente, no caso do CBS, somente no período de 1987 a 1990. Depois disso, a capacidade de resposta do hospital ficou extremamente rápida, devido essencialmente às mudanças em sua estrutura e de seus processos, que se tornaram mais ágeis.

\section{CONCLUSÃO}

Este estudo teve como objetivo principal explicar o processo de mudança estratégica de uma organização hospitalar baseando-se num caso empírico. A idéia básica era conhecer as condições objetivas do setor hospitalar - o ambiente real, bem como a arena cognitiva - e o ambiente subjetivo, ou seja, como o ambiente é percebido pela coalizão dominante do hospital. Foi possível comprovar que, como afirmam Ashmos e McDaniel Jr. (1991), a estratégia adotada por um hospital (no caso específico, o CBS), é consubstanciada na visão que faz do mundo hospitalar, na sua interpretação do ambiente e nos valores e nas bases cognitivas da sua coalizão dominante. A rede colaborativa também foi foco de discussão, a fim de conhecer as atividades que deram suporte às mudanças estratégicas do hospital. Com os três elementos, ficou mais fácil explicar todo o processo de mudança que ocorreu no hospital.

Da coalizão dominante do CBS fazem parte a Diretoria Executiva, a Mesa Administrativa e o Conselho Pleno, e foi possível dividir a rede colaborativa do hospital em quatro elementos principais: a) os recursos humanos; b) os recursos financeiros, incluindo o fornecimento de materiais que dão suporte à sua atividade, como o fornecimento de medicamentos; c) a tecnologia e d) os processos, incluindo os novos serviços provenientes das novas tecnologias e da agilidade dos próprios processos. Entretanto, para entender melhor quais as mudanças que se efetivaram no hospital e por que elas ocorreram, a análise foi dividida em cinco períodos:

a) de 1782 a 1965: período da fundação do hospital, em 1782, até 1965, quando a Faculdade de Medicina se instalou nas dependências do Hospital
CBS, com o objetivo de ensinar a prática médica. Foi um período sem grandes transformações, com o "hospital" funcionando apenas como um asilo. Só em 1965, com a instalação da Faculdade de Medicina em suas dependências, é que aconteceu uma mudança significativa.

b) de 1965 a 1980: foi o período áureo do hospital, pois os recursos financeiros, tecnológicos e para a manutenção do hospital provinham do governo federal. Todas as despesas eram pagas pelo Estado, pois o Hospital-Escola lá estava instalado. Mesmo com recursos fáceis, o CBS não se preocupava em aproveitá-los de maneira efetiva. Foi um período de grande inação em termos de transformações no CBS.

c) de 1980 a 1987: nesse período, com a transferência da Faculdade de Medicina para o HU, nas dependências da UFSC, o CBS começou a enfrentar sérios problemas de todas as ordens, pois os recursos fáceis não existiam mais. O hospital começou a fechar algumas de suas alas, visto que não tinha condições de manter o funcionamento em plena capacidade. O hospital viveu, nesse terceiro período, o seu pior momento, chegando quase a ir à bancarrota, porque não tinha os recursos do governo federal e seu quadro de profissionais não estava preparado para trabalhar por conta própria.

d) de 1987 a 1990: à luz dos problemas do período anterior, um grupo de 20 a 30 médicos começou a se mexer a fim de conscientizar, primeiro, todo o corpo clínico de que algo teria de ser feito, porque, senão, o CBS fecharia suas portas por completo. Por meio de um processo de conscientização, o movimento de médicos que ia se engajando no processo de implementar mudanças aos poucos crescia, muito embora existissem forças que eram contra o processo de transformação do hospital. A mudança de um estado de inércia total da organização diante das mudanças ambientais para um projeto de viabilizar mudanças organizacionais a fim de adaptar o CBS às novas realidades que o momento exigia preocupava uma parte do corpo clínico. Eles pensavam que poderiam ser excluídos do processo ao serem transferidos para um novo estado das coisas. Mesmo com toda essa preocupação, tais médicos não tiveram escolha, ou eram excluídos do processo desde o início ou apostavam na sorte de um "lugar ao sol", ainda que em um ambiente bem diferente daquele com o qual estavam acostumados. Com o corpo clínico conscientizado, iniciou-se um trabalho com os enfermeiros e com aqueles funcionários localizados em pontos-chave da organização. Da mesma forma, 
foi informado a essas pessoas que o CBS tinha que passar por algumas mudanças devido aos diversos problemas que enfrentava naquele momento.

e) de 1991 a 1995: no bojo de uma organização pronta para enfrentar um processo de mudança estratégica, inicia-se o quinto período, em que grandes transformações são implementadas, fazendo com que o hospital consiga sobreviver e superar as suas crises.

Em linhas gerais, pode-se dizer que a dinâmica do processo de mudança ocorreu da forma como foi descrita anteriormente. No entanto, os resultados foram consubstanciados essencialmente em cinco mudanças estratégicas, acrescentando-se que essas mudanças não são estanques, todas elas estão relacionadas umas com as outras: (a) com o processo de conscientização, houve uma mudança no comportamento e, conseqüentemente, na forma de trabalho e treinamento, bem como nas próprias atitudes de médicos e funcionários, gerando, com isso, também uma (b) mudança cultural nessas duas classes e, por conseguinte, na própria cultura do CBS. Assim, o hospital mudou tanto a forma de atuar dos médicos como a forma de treinamento dos próprios funcionários.

Devido às duas mudanças anteriores, (c) os processos, tanto o administrativo/gerencial quanto o operacional, foram agilizados. O exemplo mais claro é a questão dos médicos não deixarem para depois o que podem fazer no mesmo dia. Desse modo, as altas médicas, que eram analisadas sem muita pressa, passaram a ser um fator de extrema importância, visto que a nova concepção moldada para o CBS pressupunha que o paciente não pudesse ficar nem mais um minuto no hospital se não houvesse necessidade. Na mesma linha de pensamento, a (d) estrutura organizacional no que tange a atos estritamente de competência dos médicos foi flexibilizada. Não confundir com flexibilidade dos poderes da coalizão dominante, porque isso não ocorreu.

Por fim, com o advento das clínicas ao CBS, chegou também tecnologia médica de ponta. A (e) mudança tecnológica só foi possível quando os médicos foram chamados para cooperar financeiramente no processo de mudança. Para o hospital, as vantagens são enormes, uma das principais é que as clínicas se comprometeram em contrato a estar sempre à disposição do CBS quando este precisar encaminhar os seus pacientes.

Assim, um ponto muito importante a ser destacado é a questão da proatividade da tecnologia influindo na postura estratégica do CBS e, por conseguinte, gerando e impulsionando mudanças estratégicas, ou seja, modificando o comportamento estratégico do Hospital CBS. Portanto, por um lado, o estudo corrobora as pesquisas de Teplensky et al. (1995), confirmando que a adoção de novas tecnologias por parte de organizações hospitalares pode ser resultado da coalizão dominante e, por outro, tem um caráter inovador ao constatar que a tecnologia pode ser o único elemento influenciador no comportamento estratégico de uma organização hospitalar.

\section{As mudanças no hospital foram estritamente reativas e não planejadas. Hoje, diferentemente, elas são planejadas e proativas, à luz da percepção do ambiente pela coalizão dominante do hospital.}

Juntando-se os dois pontos de vista, consegue-se constatar que os estudos de Swan (1995) são verdadeiros, pois eles argumentam que, em processo de inovação ou mudança tecnológica, os sucessos ou fracassos podem ser atribuídos aos tomadores de decisões ou, melhor dizendo, à coalizão dominante. Esse fato ocorreu com o CBS no momento em que a coalizão dominante, numa decisão inovadora e criativa, convidou os médicos a participarem financeiramente na gestão do hospital, levando-o ao que ele é hoje: um hospital de referência em todo o estado. Sendo, assim, um caso muito diferente de toda a realidade brasileira.

Por tudo isso, fica claro que o processo de mudança estratégica no Hospital CBS foi estritamente reativo e não planejado. Muito diferente dos métodos que estão sendo aplicados atualmente, ou seja, as mudanças são planejadas e proativas, à luz da percepção do ambiente pela coalizão dominante do hospital, principalmente no que tange às novas tecnologias incorporadas aos processos do hospital. Como disse um dos Diretores do CBS, “(...) no momento em que uma nova tecnologia é incorporada, o CBS já começa a buscar caminhos para sanar o problema da defasagem que essa própria tecnologia gerará nos próximos três anos".

O processo de mudança tecnológica levou o Hospital CBS a se diferenciar dos demais em termos de condições objetivas: a) por ser o único hospital do estado que oferece todas as especialidades médicas, diferentemente dos outros, que se centram em apenas algumas; b) por ser o único hospital do estado que possui um aparelho de radioterapia com acelerador linear, última palavra em tecnologia sobre o assunto e c) por ser o único hospital no Brasil a oferecer serviços psiquiátricos. 
A mudança mais importante no CBS foi a tecnológica. A terceirização e a parceria feita com os médicos, via construção de clínicas nas dependências do hospital, possibilitaram ao CBS chegar à tecnologia de ponta, fato que, de outra forma, seria impossível. Com isso, além dos médicos de renome que o hospital já possuía, foi possível a diversificação dos serviços oferecidos pelo CBS.

Logo, as rápidas mudanças tecnológicas pelas quais passa o setor hospitalar exigem, por parte do CBS, uma configuração organizacional adaptativa às demandas ambientais. Em vista disso, como argumentou um dos
Diretores do hospital, se o CBS não buscar aquilo que há de mais avançado no campo da tecnologia hospitalar, perderá seus melhores profissionais, que marcharão em direção a hospitais mais bem equipados.

Nesse sentido, a principal preocupação estratégica do Hospital CBS é procurar servir a população cada vez mais e melhor, apresentando bons serviços médicos. Para isso, o hospital busca, por meio da sua arena cognitiva, ou seja, pelo ambiente percebido pela coalizão dominante, formas de estar sempre à frente dos demais hospitais, oferecendo bons serviços, médicos qualificados e tecnologia de última geração.

\section{REFERÊNCIAS BIBLIOGRÁFICAS}

ALEXANDER, J. A. Adaptive change in corporate contro practices. Academy of Management Journal, v. 34, n. 1, p. 162 193, Mar. 1991

ASHMOS, D. P., McDANIEL JR., R. R. Physician participation in hospital strategic decision making: the effect of hospital strategy and decision content. HSR: Health Services Research, v. 26 n. 3, p. 375-401, Aug. 1991

BITTAR, 0. J. N. V., MIELDAZIS, E. J. Considerações sobre recursos de saúde, economia e demografia brasileiras. Revista de Administração Pública, v. 26, n. 3, p. 107-118, jul./set. 1992.

BOWDITCH, J. L., BUONO, A. F. Elementos do comportamento organizacional. São Paulo : Pioneira, 1992.

BRUYNe, P., HERMAN, J., SCHOUTHEETE, M. Dinâmica da pesquisa em ciências sociais: os pólos da prática metodológica. Rio de Janeiro : Francisco Alves, 1991.

CASTELAR, R. M. 0 hospital no Brasil. In: CASTELAR, R. M., MORDELET, P., GRABOIS, V. Gestão hospitalar. um desafio para o hospital brasileiro. Rennes : ENSP, 1995. p. 38-49.

CHILD, J. Organizational structure, environment and performance: the role of strategic choice. Sociology, v. 6, n. 1 , p. 1-22, 1972.

CHILD, J., SMITH, C. The context and process of organizationa transformation: Cadbury Limited in its sector. Journal of Management Studies, v. 24, n. 6, p. 565-593, Nov. 1987.

CRAVENS, D. W., SHIPP, S. H., CRAVENS, K. S. Reforming the traditional organization: the mandate for developing networks. Business Horizons, v. 37, n. 4, p. 19-28, July/Aug. 1994.

DRUCKER, P. F. Administração em tempos de grandes mudanças. São Paulo : Pioneira, 1995.

DUNPHY, D. C., STACE, D. A. Transformational and coercive strategies for planned organizational change: beyond the 0 . D. model. Organization Studies, v. 9, n. 3, p. 317-334, 1988.

FERGUSON, M. A conspiração aquariana. 3. ed. Rio de Janeiro : Record, 1980

GLADSTEIN, D., QUINN, J. B. Making decisions and producing action: the two faces of strategy. In: PENNINGS, J. M. et al. Organizational strategy and change: new views on formulating and implementing strategic decisions. San Francisco : JosseyBass, 1985. p. 198-216.

GREENWOOD, R., HININGS, C. R. Organizational design types, tracks and the dynamics of strategic change. Organization Studies, v. 9, n. 3, p. 293-316, 1988.

GRONHAUG, K., FALKENBERG, J. S. Exploring strategy perceptions in changing environments. Journal of Management Studies, v. 26, n. 4, p. 349-359, July 1989.
GUTIERREZ, L. H. S. Recursos humanos em um contexto de reestruturação. Revista de Administração, v. 31, n. 1, p. 97103, jan./mar. 1996.

HALL, R. H. Organizações: estrutura e processos. 3. ed. Rio de Janeiro : Prentice-Hall do Brasil, 1984.

HEGARTY, W. R. Organizational survival means embracing change. Business Horizons, v. 36, n. 6, p. 1-4, Nov./Dec. 1993.

HUTT, M. D., WALKER, B. A., FRANKWICK, L. G. Hurdle the crossfunctional barriers to strategic change. Sloan Management Review, v. 36, n. 3, p. 22-30, Spring 1995.

JUDSON, A. S. Relações humanas e mudança organizacional. São Paulo : Atlas, 1980

KIKULIS, L. M., SLACK, T., HININGS, C. R. Sector-specific patterns of organizational design change. Journal of Management Studies, v. 32, n. 1, p. 67-100, Jan. 1995.

KIRKPATRICK, D. L. How to manage change effectively: approaches, methods, and case examples. San Francisco Jossey-Bass, 1988

McKINLAY, A., STARKEY, K. Competitive strategies and organizational change. Organization Studies, v. 9, n. 4, p. 555$571,1988$.

MÉDICI, A. C. Economia e financiamento do setor no Brasil: balanços e perspectivas do processo de descentralização. São Paulo : Faculdade de Saúde Pública/USP, 1994.

MILES, R., SNOW, C. Organization strategy. structure and processes. New York : McGraw-Hill, 1978.

NADLER, D. A., HACKMAN, J. R., LAWLER III, E. E. Comportamento organizacional. Rio de Janeiro : Campus, 1983. p. 45.

PETERS, T. Rompendo as barreiras da administração: a necessária desorganização para enfrentar a nova realidade. São Paulo : Harbra, 1993

PETTIGREW, A. M. Examining change in the long-term context of culture and politics. In: PENNINGS, J. M. et al. Organizational strategy and change: new views on formulating and implementing strategic decisions. San Francisco : Jossey-Bass, 1985. p. 269-318.

PETTIGREW, A. M. A cultura das organizações é administrável? In: FLEURY, M. T. L. Cultura e poder nas organizações. São Paulo : Atlas, 1990

PETTIGREW, A. M., FERLIE, E., McKEE, L. Shaping strategic change: making change "in large organization". London : Sage, 1992.
PITTA, A. Hospital: dor e morte como ofício. São Paulo : Hucitec 1994

PROVAN, K. G. Receipt of information and influence ove decisions in hospitals by the board, chief executive officer and medical staff. Journal of Management Studies, v. 28, n. 3 p. 281-298, May 1991.

REYNIERSE, J. H. Ten commandments for CEOs seeking organizational change. Business Horizons, v. 37, n. 1, p. 40-45 Jan./Feb. 1994.

RIBEIRO, H. P. Políticas de saúde e assistência médica no Brasil. In: ROUQUAYROL, M. Z. Epidemiologia \& Saúde. Fortaleza : Unifor/CNPq, 1983

ROBBINS, S. P. Organization theory. structure, design, and applications. 3. ed. Englewood Cliffs : Prentice-Hall, 1990.

SCHREUDER, H. Timely management changes as an element of organizational strategy. Journal of Management Studies, v. 30 n. 5 , p. $723-738$, Sep. 1993

SELLTIZ, C. et al. Métodos de pesquisa nas relações sociais São Paulo : EPU, 1974

SWAN, J. A. Exploring knowledge and cognitions in decisions about technological innovation: mapping managerial cognitions. Human Relation, v. 48, n. 11, p. 1241-1270, 1995

TEPLENSKY, J. D. et al. Hospital adoption of medical technology: an empirical test of alternative models. HSR: Health Services Research, v. 30, n. 3, p. 437-465, Aug. 1995

THEOBALD, R. New success criteria for a turbulent world. Planning Review, v. 22, n. 6, p. 10-13/43, Nov./Dec. 1994.

TOFFLER, A. O choque do futuro. Rio de Janeiro : Record, 1970.

VAN DE VEN, A. H. Suggestions for studying strategy process: a research note. Strategic Management Journal, v. 13, p. 169 188, 1992.

VASCONCELOS, I. F. F. G. IBM: o desafio da mudança. RAE Revista de Administração de Empresas, v. 33, n. 3, p. 84-97, maio/jun. 1993

VIANA, A. L., QUEIROZ, M. S., IBANEZ, N. Implementação do Sistema Unico de Saúde: novos relacionamentos entre os setores público e privado no Brasil. Revista de Administração Pública, v. 29, n. 3, p. 17-32, jul./set. 1995.

WOOD JR , T CURADO, I. B., CAMPOS, H. M. Vencendo a crise: mudança organizacional na Rhodia Farma. RAE - Revista de Administração de Empresas, v. 34, n. 5, p. 62-79, set./out. 1994

YIN, R. K. Case study research: design and methods. Beverly Hills : Sage, 1989 